\title{
Proyectos para una nueva frontera. La diplomacia norteamericana y el noroeste de México. 1861-1862
}

Marcela Terrazas $B$.

\begin{abstract}
Parte de la semántica imperial norteamericana, el término frontier no denota fundamentalmente el límite territorial entre dos países [border, borderlands] evoca más que nada la noción de un nuevo campo, de algo incompleto y desafiante susceptible de llenarse por la voluntad de poder. ${ }^{1}$
\end{abstract}

uando Frederick Jackson Turner publicó en 1893 su artículo "La frontera en la historia americana", apareció a la luz un intento de encontrar nuevas claves de interpretación de la historia de los Estados Unidos.

Con un enfoque entonces novedoso, Turner trató de explicar las peculiaridades históricas de esa nación como resultado de una frontera que, al contrario del concepto europeo de confín o límite, se presenta como un espacio abierto a la expansión. Ahí en la frontera -señaló Turner- se forjaron la democracia, el individualismo, los rasgos idiosincráticos del norteamericano y ahí también el desarrollo capitalista estadunidense cobró singularidad por la existencia de la frontera.

A pesar de que las tesis turnerianas, que en su momento despertaron amplia polémica, han quedado atrás, no puede dejarse de considerar cómo la "frontier" modificó, matizó o marcó aspectos sustanciales en el desarrollo de los Estados Unidos: la naturaleza del Estado, las contradicciones sociales, el avance de la industrialización, la formación de la clase obrera y su organización; el proceso histórico en su conjunto se vio moldeado por este fénómeno. El expansionismo (presente desde la fundación del primer asentamiento anglosajón en la Bahía de Massachusetts, 1607) dejó su impronta en buena parte del siglo XIX norteamericano.

Durante la guerra de Secesión el avance de esa línea imprecisa y móvil quedó suspendido. El conflicto entre el modelo de desarrollo agroexportador de plantación y el proyecto industrialfinanciero estalló irremediablemente.

La lucha entre el Norte y el Sur que en esos momentos tomó forma en un brutal conflicto bélico absorbió muchas energías de

1 José Luis Orozco, El testimonio politico norteamericano (1890-1980), México, SEP/UNAM, 1982, 2 vols., vol. I, p. 5.

2 Frederick Jackson Turner, "La frontera en la historia americana", en Secuencia, Revista Americana de Ciencias Sociales, México, enero-abril, 1987, núm. 8, p. 186-207.

${ }^{3}$ Sobre la incidencia de la frontera en la formación y organización de la clase obrera norteamericana véase: José Miguel Insulza, "Notas sobre la formación de la clase obrera y el movimiento sindical en Estados Unidos", en Cuadernos Semestrales. Estados Unidos: Perspectiva Latinoamericana, México, CIDE, núm. 11, primer semestre de 1982, p. 17-63. 
ambas partes; pero las fuerzas que pujaban por continuar con el corrimiento de la frontier no cejaron en sus propósitos. México, que ya habia sufrido los efectos de ese avance (Texas: 1836, Alta California y Nuevo México: 1846-1848, La Mesilla: 1853) era de nueva cuenta escenario del expansionismo que ahora llegaba por partida doble: la Unión y la Confederación.

El conflicto en los Estados Unidos se entretejió con un México donde las dificultades politicas, la inestabilidad social y la grave crisis económica movieron a la administración de Juárez a decretar la suspensión del pago de la deuda (julio 17, 1861). La medida del gobierno mexicano dio pie a la intervención de Inglaterra, Francia y España, abrió el camino a los planes conservadores de recuperar el poder y a los designios napoleónicos de establecer un imperio. La circunstancia -cabe resaltar- era particularmente singular: para los Estados Unidos de Norteamérica y para México definir el proyecto socioeconómico, y en el caso de México también político, que habrian de adoptar.

Matias Romero, ministro de Juárez ante el gobierno de Abraham Lincoln, observó los proyectos de tres importantes sectores políticos norteamericanos en el momento de iniciarse la guerra de Secesión. Romero advirtió que los esclavistas ya separados de la Unión estaban enteramente resueltos a apoderarse de todo el territorio mexicano y por el momento se disponian a adueñarse de los estados fronterizos. Hizo notar que los secesionistas pondrian en práctica el filibusterismo, debido a las dificultades para negociar la adquisición de tierras.

El mexicano apuntó también que los demócratas que aún permanecian en la Unión en todo pensaban menos en desistir de sus propósitos respecto a la adquisición de territorios en México, ${ }^{5}$ y a pesar de verse obligados a moderar la sinceridad de su lenguaje, mantenían las mismas pretensiones expansionistas que los demócratas que habian dejado la federación. ${ }^{6}$

Por su parte los republicanos, temerosos de una invasión confederada a México, se declararon dispuestos a impedir los planes sureños; consideraron que de no hacerlo, el Sur extendería su poder e influencia. Militantes prominentes de aquel partido expresaron a Romero su determinación de establecer un protectorado sobre la República Mexicana con tal de frenar el avance de los esclavistas.

El gobierno de la Unión designó a Thomas Corwin ministro extraordinario y plenipotenciario ante la administración de Juárez. Antiguo miembro del partido Whig, político experimentado y gran orador, Corwin gano notoriedad por su ardiente oposición a la guerra contra México.

En esa ocasión declaró desde la tribuna del Senado su esperanza

\footnotetext{
4 Matías Romero al ministro de Relaciones Exteriores, Washington, febrero 21, 1861, en Matías Romero (ed.), Correspondencia de la legación mexicana en Washington durante la intervención extranjera, 1860-1868, introd. de..., México, Imprenta del Gobierno en Palacio, 1870-1892 (Colección de documentos para formar la Historia de la Intervención), 10 vols., vol. I, p. 692-693.

s. Idem.

${ }^{6}$ Idem.

${ }^{7}$ Romero al ministro de Relaciones Exteriores, Washington, marzo 9, 1861, en Romero, ibid., vol, I, p. 695.
} 
de que "los mexicanos recibieran a los ejércitos invasores con las manos ensangrentadas y sepulcros hospitalarios". 8

El nuevo embajador debía evitar que Juárez reconociera a los secesionistas e impedir la influencia de éstos en la República. Procuraria asegurar al gobierno mexicano la oposición de Lincoln a los proyectos expansionistas de los confederados y expresaría el deseo del presidente de establecer relaciones "con un espiritu desinteresado y sin ambiciones".?

La administración republicana anunció por boca de Corwin el principio de una nueva era en las relaciones entre los dos países.

Tal como Romero lo había anticipado, las manifestaciones de los propósitos de la Confederación de adueñarse de territorio mexicano se multiplicaron.

El gobernador de Carolina del Sur declaró la resolución de los esclavistas de repartirse México en caso de que éste se aliara con la Unión. Las expediciones filibusteras sobre Baja California asolaron la región. La Secretaría de Estado norteamericana que hasta el momento no había mostrado mayor interés en impedir tales incursiones, abandonó su actitud indolente al verificar los informes de los planes secesionistas para apropiarse de la peninsula como primer paso para invadir México. William H. Seward, secretario de Estado, solicitó autorización al gobierno juarista para intervenir militarmente en México en caso de una invasión confederada; ${ }^{10}$ aseguró que aun cuando los Estados Unidos no deseaban adquirir territorio mexicano, estarian dispuestos a comprar la Baja California o cualquiera otra entidad con tal de evitar que el Sur se apoderara de ella."

Seward coincidió con su ministro en que la Baja California era el territorio más valioso para los intereses norteamericanos. Sus argumentos sobre el escaso valor de esas tierras para México, la falta de población y el abandono en que se hallaba la región, recordaban el discurso de John Forsyth, William Churchwell o Robert Milligan McLane, diplomáticos que precedieron a Corwin y reconocidos expansionistas. Asi pues, las ambiciones territoriales que los viejos políticos demócratas habían manifestado en el pasado no diferian demasiado de las que ahora mostraban los flamantes republicanos que ocupaban el poder, cuyo interés por la entidad rebasaba el simple deseo de impedir que cayera en manos enemigas.

Las presiones tanto del gobierno de la Unión como del confederado sobre México eran constantes. El gobierno de la República se vio en graves aprietos cuando William Seward solicitó su autorización para que tropas de la Unión transitaran por Sonora. ${ }^{12}$

\footnotetext{
${ }^{8}$ Alfred Jackson Hanna y Kathryn Abbey Hanna, Napoleón III y México, trad. de Ernestina Champourcin, México, Fondo de Cultura Económica, 1973, p. 48.

${ }_{9}$ William H. Seward a Thomas Corwin, Washington, abril 6, 1861, en EE.UU. National Archives, Records of the Department of State, MP (ms), Diplomattc Insiructions 1801-1906 Mexico, rollo 113, fol. 146-7. De aqui en adelante citaremos: EE.UU. National Archives Records of the Department of State con las siglas NAW.

${ }^{10}$ Corwin a Seward, Washington, junio 3, 1861, NAW, rollo 13, fol. 351-352.

11 Idem.

12 Seward a Romero, Washington, mayo 7, 1861, en Romero, op. cit, vol. I, p. 721-722.
} 
La petición se discutió en el Congreso de México donde se hizo ver que podría provocar la hostilidad de los secesionistas, quienes la tomarían como pretexto para la ocupación del suelo nacional. No obstante el peligro que representaba, los diputados consideraron necesario acercarse al gobierno del Norte, pues juzgaban inminente una invasión de los sureños si éstos se separaban de la Unión. ${ }^{13}$ Con estas consideraciones, el gobierno de Juárez autorizó el desembarco de tropas unionistas en Guaymas y su paso por Sonora.

Al publicarse la noticia en los diarios estadunidenses, los confederados amenazaron con lanzar sus ejércitos desde Texas, donde levantarian 20000 hombres. $^{14}$

Romero, inquieto, escribió a su gobierno. Las amenazas lanzadas por los secesionistas podían ser exageradas (él no tenía argumentos para afirmar lo contrario), pero su temor obedecía en buena medida a que las propias potencias habian declarado su neutralidad y a la reciente victoria de Bull's Run $^{15}$ que ensoberbeció a los sureños. Su aprensión debió aumentar al enterarse de un proyecto de alianza entre Nuevo León, Chihuahua, Sonora, Baja California y los estados secesionistas y al saber la difícil situación política en Chihuahua donde, ante la proximidad de las elecciones, se había formado un partido opositor al gobierno de Luis Terrazas. Esta división podría tener consecuencias fatales para la Reforma y favorecer las ambiciones confederadas de conquista. ${ }^{16}$

La República se hallaba en situación crítica. Esto no sólo obedecía a las amenazas de la Confederación de apoderarse del norte del país o a los proyectos de algunos mexicanos de aliarse a ella, sino primordialmente al desastroso estado financiero del erario. Tal era la razón que impedía al gobierno constitucional terminar con las bandas reaccionarias que aún asolaban a la población, y establecer la paz definitiva.

El gobierno de Juárez decidió el 17 de julio de 1861 suspender el pago de la deuda pública (inclusive la externa) durante dos años. La medida irritó a los gobiernos de Inglaterra y Francia que, por medio de sus comisionados Sir Charles Wyke y Alphonse Dubois de Saligny, exigieron la suspensión inmediata del decreto. La negativa mexicana provocó la ruptura de relaciones y la intervención armada pareció inevitable.

Corwin escribió un largo comunicado al Departamento de Estado donde señalaba sus temores acerca de una intervención extranjera o de una partición de territorio. ${ }^{17}$ Dijo también que Inglaterra y Francia parecían estar actuando en concierto con el fin de intimidar al gobierno mexicano y obligarlo a anular la disposición

${ }^{13}$ Romero a Seward, Washington, junio 21, 1861, NAW, Dispatches from U.S. Ministers to Mexico 1823-1906, rollo 29, vol. 28.

${ }_{14}$ Romero al ministro de Relaciones Exteriores, Washington, julio 30, 1862, en Romero, op. cit., vol I, p. 476.

15 Idem.

${ }^{16}$ Guadalupe Miranda, antiguo vicecónsul de México, en Franklin, Nuevo. México, envió a Romero una nota sobre este asunto que aparece en Romero al ministro de Relaciones Exteriores, Washington, julio 29, 1861, en Romero, ibid., vol. I, p. 475.

"Corwin a Seward, México, julio 29, 1861, NAW, rollo 29, vol. 28. 
o "como la forma más rápida y segura de iniciar un movimiento que terminaría en la ocupación de la frontera marítima y que llevaría de manera inevitable a la posesión de todo el interior". 18

"Los Estados Unidos son los únicos guardianes seguros de la independencia de este continente. Es su misión y deben realizarla..." 19 escribió el ministro e instó a su gobierno a tomar medidas: propuso que los Estados Unidos se hicieran cargo de los intereses de los tenedores de bonos ingleses cinco años. "Estoy persuadido de que México estaría dispuesto a empeñar todas sus tierras públicas y los derechos mineros de Baja California, Chihuahua, Sonora y Sinaloa, así como su palabra nacional por el pago de esa garantía. Esto acabará probablemente en la cesión de soberanía a nuestro favor." ${ }^{20}$ El proyecto de Corwin pretendía fortalecer al gobierno de Juárez mediante un préstamo e impedir tanto a los confederados como a las monarquías europeas lanzarse sobre México, al tiempo que contenía la propuesta para una nueva frontera; Baja California, Sonora, Chihuahua y Sinaloa (los codiciados territorios) pasarian a manos norteamericanas cuando México, "tremendamente empobrecido por cuarenta años de guerra civil", "i no pudiera cumplir su compromiso.

El secretario de Estado norteamericano escribió a su intranquilo ministro. Dijo que en vista de la grave situación mexicana, el gobierno norteamericano estaba resuelto a facultarlo para negociar un tratado en el cual los Estados Unidos se comprometían a pagar el 3\% de los intereses a los tenedores de bonos, el principal de los cuales era de $\$ 62000000.00$, durante cinco años, a partir de la fecha del decreto de suspensión de pagos. ${ }^{22}$

México pagaria el $6 \%$ de los intereses con garantía en una hipoteca sobre todos los terrenos públicos y derechos mineros en los estados de Baja California, Sonora, Chihuahua y Sinaloa. Estos pasarian a propiedad estadunidense si México no pagaba antes de seis años. ${ }^{23}$ Seward advirtió a Corwin que la condición para efectuar el tratado era obtener la seguridad de que los gobiernos de Francia e Inglaterra desistirian de sus propósitos de intervenir en México. Ya había dado instrucciones a sus embajadores en Francia e Inglaterra para tratar el asunto y le pidió obtuviera la respuesta mexicana. ${ }^{24}$

Cuando don Matías Romero tuvo en sus manos el proyecto, escribió indignado: "[el tratado] equivale a una venta mal disimulada por una cantidad bastante miserable". 25 Al mismo tiempo le pareció poco probable que Francia e Inglaterra lo aprobaran. La única ventaja que vio en el acuerdo fue que la mediación norteamericana evitaría que las potencias se precipitaran sobre su país,

${ }^{18}$ Idem.

19 Idem.

20 Idem.

21 Expresión usada por el propio Corwin.

2 Seward a Corwin, Washington, agosto 24,1861 , NAW, rollo 113 , fol. 363365.

Idem.

24 Idem.

25 Romero al ministro de Relaciones Exteriores, Washington, septiembre 13, 1861, en Romero, op. cit., vol. I, p. 731 . 
dando el tiempo necesario al gobierno de la República para resolver lo más conveniente. ${ }^{26}$

Seward escribió de nuevo a Corwin y le pidió que hiciera cuanto pudiera para lograr la firma del tratado. ${ }^{27}$

En México, la situación financiera del gobierno era desesperada, al grado que Manuel Maria Zamacona, ministro de Relaciones Exteriores, dio instrucciones a Romero para conseguir un préstamo de $\$ 10000000.00$ entre los comerciantes de Nueva York. El gobierno de la República no tiene crédito entre los capitalistas de esa ciudad, contestó Romero, ellos consideran que el nuestro es un país en eterno desorden que sólo terminará cuando Europa o los Estados Unidos lo conquisten. ${ }^{28}$

El ministro de Relaciones Exteriores, entretanto, entró en tratos con el embajador inglés, Sir Charles Wyke. Después de meses de negociación, ambos firmaron un tratado en el que se restablecian las relaciones entre los dos países, se derogaba la ley del $17 \mathrm{de}$ julio de 1861 (la de suspensión de pagos), se reducían en $50 \%$ las tarifas aduanales para los productos británicos y se estipulaba la actuación de interventores británicos en la recaudación de los ingresos de las aduanas para salvaguardar los intereses de los tenedores de bonos. ${ }^{29}$

Paralelamente al acuerdo con el ministro británico, Zamacona entró en arreglos con Thomas Corwin sobre los puntos del tratado con los Estados Unidos. El norteamericano introdujo modificaciones importantes a lo propuesto por Seward; éstas eran: 1) los Estados Unidos prestarían a México $\$ 11000000.00$ en lugar de los $\$ 9450000.00$ originales; 2) la garantia del préstamo quedaría constituida por todas las tierras públicas y propiedades nacionales pertenecientes anteriormente a la Iglesia, que el embajador estimaba en $\$ 100000000.00 .^{30}$

Tal como Corwin subrayó con este proyecto, el préstamo a México se incrementó tan sólo en $\$ 1500000.00$, en tanto que las garantías se hicieron absolutas y se aseguró la posibilidad de que México pagara una gran parte del adeudo antes de que se le diera todo el dinero, de tal forma que la operación podría cerrarse en cuatro años. 31

El nuevo tratado estableció asimismo, que cinco personas -tres nombradas por el presidente de México y dos por el de los Estados Unidos- tendrían los poderes gubernamentales para supervisar y vender las tierras públicas, así como para garantizar los derechos

$2 \hat{6}$ Idem.

${ }^{27}$ Seward a Corwin, Washington, septiembre 29, 1861, NAW, rollo 113, fol. 375-377.

${ }_{28}$ Romero al ministro de Relaciones Exteriores, Washington, octubre 2,1861, en Romero, op. cit., vol. I, p. 735 .

29 Manuel Ma. Zamacona e Inclán, ministro de Relaciones Exteriores a Sir Charles Wyke, comisionado del gobierno de Su Majestad Británica en México. México. noviembre 21,1861 , en México y la Gran Bretaña durante la Intervención 1861-1862, introducción, selección y traducción de Gloria Grajales, México, Secretaría de Relaciones Exteriores, 1974, 2a. ed., 241 p. (Col. del Archivo Histórico Diplomático Mexicano, 3a. época, serie documental núm. 9), p. 112-113.

${ }^{30}$ Corwin a Seward, México, octubre 29, 1861, NAW, rollo 29, vol. 28.

3 Idem. 
mineros y cobrar las sumas vencidas sobre las propiedades ecle-
siásticas.

El norteamericano dijo a Seward que Wyke habia expresado al Ministerio del Exterior en Londres que su arreglo era todo cuanto el gobierno inglés podia esperar. Aseguró asimismo que el gobierno francés estaría satisfecho con los convenios. En cualquier caso -agregó- el dinero a pagar por los Estados Unidos sobre el interés de la deuda francesa y española, no sobrepasaría los $\$ 150000.00$ anuales. Corwin reiteró la necesidad de ayudar a mantener al gobierno de la República y aseguró que el préstamo era indispensable. ${ }^{33}$

El comisionado de los Estados Unidos tenía razón, la situación de México no podía ser más crítica (la Convención de Londres se firmó dos días después de este despacho) y los acuerdos tenian que ser tomados con apremio. No obstante, el nuevo proyecto denotaba ante todo la habilidad del diplomático para sacar partido del apuro: el tiempo de crédito se reducía de seis a cinco años, cinco de los once millones del préstamo se darían a México en entregas mensuales y el resto en tres pagos anuales, de tal forma que el pago se acabaría de hacer en cinco años, mientras se calculaba que México liquidaría su deuda en cuatro años y lo más grave: todas las tierras públicas y derechos mineros quedaban empeñados a los Estados Unidos.

Para terminar de convencer a su gobierno de las virtudes del tratado, Corwin añadió que debido a los propósitos manifiestos de los secesionistas "...es obvia la necesidad de fortalecer a México por medio de un préstamo que le permite luchar con nuestro enemigo común en tanto que las tierras públicas de toda la República Mexicana, para enfrentarnos a los rebeldes en nuestras tierras en México, ahí podriamos unir las tropas de las dos repúblicas y sacar sus fuerzas [de los secesionistas] de Texas, lo que permitiría al partido de la Unión restablecer el gobierno legítimo en esos estados". 34

Cuando John T. Pickett, enviado de los confederados ante la República, se enteró del tratado proyectado por Corwin, advirtió al gobierno mexicano que la Confederación no consentiría la venta o hipoteca de las tierras públicas a un gobierno no-amigo. ${ }^{35}$ Con esto, dijo Corwin, los secesionistas pretenden impedir que México reciba ayuda para favorecer una intervención extranjera

\footnotetext{
3.' Idem.

3. Idem.

${ }^{34} \mathrm{El}$ subrayado es nuestro. Sobre este asunto existe una controversia, pues en la correspondencia reservada del ministro mexicano de Relaciones Exteriores, Manuel Ma. Zamacona, a don Matias Romero aparece una nota fechada en octubre 29 , 1861 , que dice que en los arreglos propuestos por Corwin se exige al gobierno de México como garantía el producto de los bienes del clero y de los terrenos baldíos y no los terrenos mismos como decian las instrucciones cuya copia recibió Romero. Esta diferencia, recalcó Zamacona, dejaba fuera de peligro la independencia y seguridad del territorio nacional. Consideró asimismo que el producto de los bienes nacionales bastaria para pagar la deuda por el periodo estipulado. Manuel Ma. Zamacona a Matías Romero, México, octubre 29, 1861, en Romero, op. cit., vol. I, p. 957.

35 Corwin a Seward, México, octubre 29, 1861, NAW, rollo 29, vol. 28.
} 
que debilite al gobierno y así poder lanzarse sobre sus territorios del norte. ${ }^{36}$

Pickett ya había amenazado invadir esa zona en vista de la autorización que dió el gobierno constitucional para el paso de tropas de la Unión por Sonora. Juárez no daba demasiada importancia a las maniobras políticas de Mr. Pickett; cuando éste le propuso devolver a México los territorios de Alta California, Nuevo México y Arizona, a cambio de restablecer el libre comercio entre los confederados y la República, el presidente de México contestó con una negativa rotunda. El comisionado sureño dio una copia de esta proposición y de la respuesta que obtuvo, a un miembro de la oposición en el Congreso mexicano, en un vano intento de provocar un ataque en contra del primer mandatario. ${ }^{37}$

Entretanto los gobiernos de Gran Bretaña, Francia y España, que habian roto las relaciones diplomáticas con México a raíz del decreto de suspensión de pagos, firmaron en Londres un convenio el 31 de octubre de 1861 en el cual acordaron enviar fuerzas armadas a ocupar puertos mexicanos, para obligar al gobierno de Juárez a cumplir sus compromisos y exigir respeto a sus súbditos y propiedades. En la Convención se estipuló que ninguna de las potencias buscaria apropiarse de territorio o intervenir en los asuntos internos de México.

En el artículo $4^{\circ}$ se invitaba a los Estados Unidos a sumarse a la Convención.

En México, el tratado Wyke-Zamacona provocó acaloradas disputas en el Congreso. Los diputados consideraron la cláusula que dejaba las aduanas bajo control británico contraria al honor y a la independencia de la República. Los votos, uno a favor, dos en contra, acabaron con el proyecto de Wyke y provocaron la renuncia de Zamacona.

Corwin escribió a Seward, furioso. Los mexicanos habían desechado el tratado con los ingleses, por lo que él se había visto forzado a retirar su propuesta, pues sus instrucciones ordenaban que el convenio con México se hiciera solamente si se evitaba una intervención europea. La ruptura con los ingleses daría paso a la invasión. ${ }^{38} \mathrm{El}$ estadunidense intentaba analizar los móviles que animaban a las potencias. Pensaba que los ingleses vendrian a México para posesionarse de las aduanas y cobrar las deudas pendientes, mientras las flotaś española y francesa apoyarían su acción. Creía que los designios españoles eran reconquistar y establecer una monarquía, aunque no podría afirmar si Francia e Inglaterra lo consentirian. Para Corwin eran menos claros los propósitos franceses. ${ }^{39}$

Pero el tropiezo del tratado inglés no paralizó al ministro norteamericano, quien se dispuso a promover un nuevo arreglo con el gobierno de Juárez. Usando sus poderes discrecionales, acordó un préstamo de $\$ 5000000.00$ que serian entregados en sumas de $\$ 500000.00$ cada seis meses con la misma garantía. ${ }^{40}$ Después del

\footnotetext{
36 Idem.

37 Idem

${ }^{38}$ Corwin a Seward, México, noviembre 29, 1861, NAW, rollo 29, vol. 28.

39 Idem.

10) Idem
} 
rechazo al tratado británico, Corwin dejó pendientes las gestiones, pero estaban dispuestos a continuar si las potencias, seguras de recibir los intereses de la deuda, desistían de sus demandas. ${ }^{41}$

El nuevo préstamo, propuesto al gobierno en momentos de extrema dificultad, significaba un ahorro para los norteamericanos de $\$ 2000000.00$ respecto a la propuesta anterior, y garantias absolutas. Asimismo, ponía de manifiesto la capacidad extraordinaria del ministro de Lincoln para sacar ventaja de las situaciones criticas. Corwin pensaba que cuando las flotas de las tres potencias se hubieran apoderado de las costas mexicanas, el país estaría dispuesto a aceptar tratados como el que había rechazado a Inglaterra: "Su orgullo nacional es tan grande -dijo- que nada excepto esta demostración de su debilidad los someterá." ${ }^{42}$ Lo que el ministro norteamericano desconocía era que tanto sus empeñosos esfuerzos como los de su colega Wyke, estaban destinados a fracasar por causa de los compromisos del gobierno inglés, y no solamente por los escrúpulos del Congreso mexicano.

El acuerdo Wyke-Zamacona importunó al gobierno británico, que en esas fechas se hallaba comprometido con Francia y España por la Convención de Londres. Ni Wyke ni Corwin se enteraron de la firma del acuerdo, sino varias semanas después, debido al tiempo que tardaban en llegar las noticias. Cuando los ingleses se vieron en la necesidad de explicar al gobierno norteamericano su rechazo a la propuesta de Corwin de hacerse cargo de los intereses de la deuda, lo hicieron en los siguientes términos: "La interpretación habitualmente adoptada en Europa es que su gobierno está dispuesto a resistir toda intervención extranjera en México, no porque se inspire en principio alguno, sino porque piensa, al correr el tiempo, absorber al país entero por su propia cuenta. De ahí que cualquier proposición, como la que he tenido el honor de recibir, basada en la hipoteca de territorio mexicano en garantía de compromisos contraídos por los Estados Unidos, naturalmente provoca la protesta de que tal paso no es más que el preliminar de la ejecutoria inevitable.", 43

Poco después, los británicos respondieron a la propuesta norteamericana de asumir el pago de los intereses de la deuda con una invitación a participar en la expedición a México. ${ }^{44}$ Seward pidió todavía una copia del tratado con México para presentarlo al presidente y al Senado; se entrevistó con Matías Romero a quien dijo que su gobierno podía ofrecer $\$ 10000000.00$ a cambio de la renovación de la concesión para construir una vía por Tehuantepec a la compañía del señor Hargous. ${ }^{45}$ Esto, dijo el

41 Idem.

4? Idem.

${ }^{43}$ Charles Francis Adams a Seward en Ralph Roeder, Juárez y su México, trad. y prol. de Raúl Noriega, México, s. e., 1958, 2a. ed., 2 vols., ils., vol I, p. 498. 44 Seward a Corwin. Washington, diciembre 5, 1861 , NAW., rollo 13 , fol. 388 389.

${ }^{45}$ La compañía de Mr. Hargous obtuvo en 1848 la concesión para construir un ferrocarril por Tehuantepec. Dicha concesión fue cedida a Hargous por Manuel Garay a quien Santa Anna otorgó tal privilegio el $1^{\circ}$ de marzo de 1842 . $C f$. Agustín Cué Cánovas, Juárez, los Estados Unidos y Europa. El tratado McLane-Ocampo, México, Editorial Grijalbo, 1970 (Col. Nuestras Cosas, 3), p. 28-35. 
funcionario, haría menos pesada la carga de la ayuda a México. ${ }^{46}$

Entretanto en México, el diario El Nacional dio el 8 de diciembre la noticia de la invasión de las fuerzas españolas que se habían adelantado a sus aliados. El gobierno de la República cerró al comercio el puerto de Veracruz y dispuso medidas para reclutar fuerzas para la defensa.

Para ese momento, el Senado norteamericano ya no estaba interesado en conceder el préstamo a México. La guerra de Secesión se encontraba en plena efervescencia; el Norte estaba muy lejos de tener asegurada la victoria. Necesitaba mantener la neutralidad gala pues uno de sus temores mayores era una alianza entre confederados y franceses, especialmente en esos momentos, cuando las relaciones con Inglaterra eran excepcionalmente dificiles. ${ }^{47}$ Así lo hizo saber Charles Sumner, miembro de la Comisión de Relaciones Exteriores del Senado, a Matías Romero, a quien dijo que no veía entonces ventaja alguna en hacer el préstamo a México. ${ }^{48}$ Importantes sectores de la sociedad norteamericana consideraban que la intervención británica en México obedecía al interés de Palmerston en encontrar un pretexto para declarar la guerra a la Unión. ${ }^{49}$

En la prensa norteamericana se habló acerca del tratado que Corwin había remitido a los Estados Unidos. Se dijo que mediante éste, México concederia varios privilegios comerciales, el arreglo de deudas pendientes y el derecho de tránsito para tropas y municiones de la Unión, a cambio de $\$ 11000000.00 .^{50}$ Los diarios señalaron también la necesidad de retirar a los ingleses de la Alianza Tripartita; esto se lograría al satisfacer los intereses de los tenedores de bonos, que era la justificación para la intervención. ${ }^{51}$ La prensa norteamericana coincidió con el punto de vista de los mexicanos y del propio Corwin, quien juzgó la intervención como un intento de España para reconquistar México y de Francia e Inglaterra para satisfacer intereses económicos. El New York Tribune publicó en diciembre de 1861 y enero de 1862 editoriales con opiniones en este mismo sentido. Una de las notas señaló que seguramente las ambiciones españolas no serian secundadas por

46 Romero al ministro de Relaciones Exteriores, Washington, diciembre 14, 1861, en Romero, op. cit., vol. I, p. 645-646.

${ }^{47}$ El 8 de diciembre de 1861 tuvo lugar el "Caso Trent" en que un barco de guerra del Norte capturó el paquebote británico Trent, donde viajaban James Mason y John Slydell, enviados de la Confederación ante los gobiernos de Londres y París. Esto provocó un incidente que estuvo a punto de desatar una guerra entre Inglaterra y la Unión. Cf. Karl Marx y Friedrich Engels, Materiales para la Historia de América Latina, trad. Pedro Scaron, Cordoba, Ediciones Presente y Pasado, 1974, 2a. ed. (Col. Cuadernos Pasados y Presente, núm. 30), p. 266.

48 Romero al secretario de Relaciones Exteriores, Washington, diciembre 22, 1861, en Romero, op. cit., vol. I, p. 650.

49 Acerca de este punto resulta interesante revisar los artículos que Marx escribió para el diario New York Daily Tribune, cuyo editor era el senador republicano radical Horace Creely; Marx, op. cit., p. 256-266.

${ }_{50}$ Esta nota apareció en el New York Daily Tribune y fue enviada por Romero al ministro de Relaciones Exteriores, Washington, diciembre 20, 1861, en Romero, op. cit., vol. II, p. 822 .

5! Tal opinión aparece en un telegrama publicado en el New York Daily Tribune y fue remitido por Romero al ministro de Relaciones Exteriores, Washington, enero 2, 1862, en Romero, op cit., vol. II, p. 822. 
Inglaterra, pero que ésta dirigia sus miras hacia la Unión a través de México, y aprovecharía la ocupación de Matamoros para obtener el algodón confederado e introducir contrabando para los sureños.

La Nochebuena de 1861, Corwin escribió a Seward una relación de lo acontecido en México. Apuntó que la intervención terminaría con la firma de tratados con Inglaterra, Francia y España, en los que México tendría que ceder una suma importante de sus ingresos. En seguida pidió autorización para concertar otro tratado en términos semejantes a los del acuerdo del 29 de noviembre de $1861^{53}$ y aseguró que el préstamo era absolutamente necesario para la existencia del gobierno y la ley en México. Corwin sostuvo que el gabinete mexicano tenía los poderes necesarios para ratificar este convenio. 5

Se percibe en los despachos de Corwin que la ansiedad de obtener la firma de los tratados iba en aumento. Su insistencia iba acompañada de indicaciones sobre los momentos más difíciles para México y más convenientes para que los Estados Unidos obtuvieran acuerdos ventajosos. Asimismo puede comprobarse que las gestiones del primer enviado republicano no difieren sustancialmente de la diplomacia demócrata, al menos en lo referente a las ambiciones territoriales. El tono, el lenguaje, la forma, cambiaron, pero la esencia expansionista subsistía, recubierta sólo por un nuevo ropaje. "El espíritu desinteresado, sin ambiciones" que marcaría el inicio de una nueva relación entre los Estados Unidos y México, había quedado relegado en aras de una hipoteca flotante sobre las tierras públicas, los derechos mineros y las propiedades de la Iglesia. El Destino Manifiesto también conducia la política republicana. Seward y su ministro en México podían probarlo.

52 Los artículos publicados en el New York Daily Tribune fueron enviados por Romero al ministro de Relaciones Exteriores, Washington, diciembre 20, 1861 y enero 2, 1862, en Romero, op cit., vol: 11, p. 822. Al enterarse el embajador mexicano en Washington de la ocupación de Veracruz, comentó la intervención en sentido similar, véase Romero al ministro de Relaciones Exteriores, Washington, enero 5. 1862, en Romero, op cit., vol. II, p. 3-4.

53. Vid stupra. p. 14.

${ }^{54}$ Corwin a Seward, México, diciembre 24, 1861, NAW, rollo 29, vol. 28. 